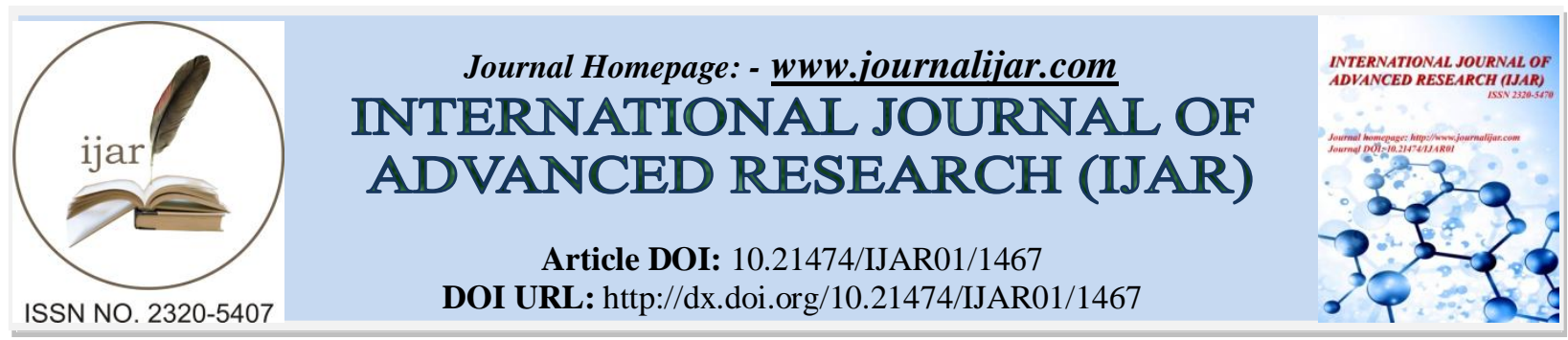

RESEARCH ARTICLE

\title{
ONLINE OPTO-THERMO-MECHANICAL STUDIES OF ISOTACTIC POLYPROPYLENE FIBRES USING MODIFIED MULTI-MODE OPTO-THERMO-MECHANICAL STRETCHING DEVICE.
}

\author{
T.Z.N. Sokkar ${ }^{1}$, M.M. El-Tonsy ${ }^{1}$, A.M. Ali ${ }^{1,2}$ and S.M. El-Khateep ${ }^{1}$.
}

1. Physics Department, Faculty of Science, Mansoura University, Mansoura 35516, Egypt.

2. Physics Department, Faculty of Science, UMM EL-QURA University, KSA.

\section{Manuscript Info}

Manuscript History

Received: 12 July 2016

Final Accepted: 22 August 2016

Published: September 2016

Key words:-

\section{Abstract}

The hot-stage multi-mode opto-thermal stretching device attached to Pluta polarising interference microscopeis used to study the online variations of the optical parameters of isotactic Polypropylene fibre as a function of the surrounding temperature. Also the variations of the birefringence profiles of isotactic Polypropylene at different stretching conditionsis studied. This device allows the online examination of the chains orientation in more details at different draw ratios and surrounding temperatures. The influence of temperature on the stretched samples and necking phenomenon was investigated using the hot-stage stretching device presented in this paper. The experimental results are supported with the microinterferograms, which are given for illustration.

Copy Right, IJAR, 2016,. All rights reserved.

\section{Introduction:-}

Isotactic polypropylene (iPP) is an outstanding thermoplastic polymer concerning its excellent cost/ performance ratio and high stiffness[1]. Polypropylene (PP) fibres and filaments are used in making many of products, such as ropes, cords, nets, woven bags, tents, geotextile components, nonwoven fabrics and reinforcing materials for various composites[2].

Structural deformation behaviour over a wide range of strain and temperature has been activelystudied from scientific and industrial aspects for many years, i.e. spherulite deformation [3],necking behaviour [4] and ultradrawability [5].Temperature is an effective parameter, which controls the drawing process of the polymeric fibres. During the stretching, there is a balance between two parameters: temperature and strain rate. A low drawing temperature implies little chain relaxation but, in this case, the strain rate takes low values, leading, on the contrary, to a larger chain relaxation [6].Undrawn synthetic fibres are almost isotropic in their physical properties. Mechanical drawing enhances different properties of textile fibres. This results stronger, more birefringence fibres that are highly anisotropic [6]. Necking phenomenon is observed during the mechanical drawing of textile fibres at room temperature, which is observed to as cold-drawing.

Based on a thermo-mechanical coupling at the neck, Barenblatt proposed the modelling of a nonlinear dynamical system. Thermo-mechanical coupling means that the work done on drawing is converted into heat. Since the deformation occurs locally at the neck, the heat increases the temperature at the neck [7]. This model based on an empirical differential equation. This equation describes the relationship between the applied stress, the necking propagation velocity and the temperature at the neck. 
Faust [8] designed an Optothermal device to study the variation of the refractive index of the fibre with the variation of that of the surrounding liquid via changes in the temperature of the interferometric system. Hamza et al. [9] studied the effect of temperature (within $15-31^{\circ} \mathrm{C}$ ) on the optical properties of Wool fibre. Hamza et al.[10] designed a hot stage attached to a multiple-beam Fizeau interferometric system to study the optical and structural properties of fibres. These studied carried out with static condition. Belal et al. [11] studied the influence of temperature on the spectral dispersion curves of refractive indices for polypropylene fibres. Hamza et al. [12] studied the influence of temperature on the mean cross-sectional area and the refractive indices of acrylic fibres. Recently, El-Dessouky [13] studied the variation of the optical and structural properties of high density polyethylene (HDPE) fibres at different temperatures.

The main task of this work is to present the online studies on the effect of temperature on the optical and structural properties of fibres. In this paper we designed and fabricated the hot-stage multi-mode opto-thermal stretching device [14] attached to Pluta polarising interference microscope. This device is used to study the online variations of the optical properties of isotactic Polypropylene fibre during the change of temperature and at different stretching conditions. This system enables the researcher to investigate the variations of the macroscopic structural properties during the stretching and/or increasing the temperature. This system also enables the researcher to investigate the effect of temperature on the necking phenomenon.

\section{Experimental technique:-}

Sokkar et al. [14] designed a multi-mode opto-thermo mechanical stretching system to determine dynamically the mechanical, optical and structural properties of fibres. This system is designed to be coupled with the well-known Pluta polarising interference microscope. The setup of this system used in this work is shown in figure (1). This system had four action modes: longitudinal testing mode, dynamic stretching mode, one point stretching mode [14] and thermo-mechanical mode.

In this paper we are concerning with the last mode. This mode of operation helps to detect the structural variations of fibres at elevated temperature. This is done with the help of a heater attached to the stretching device. A temperature controller is connected to the heater to allow controlling the surrounding temperature. At this mode of operation, the multi-mode opto-thermo-mechanical stretching device [14] is configured to study the effect of varying the temperature on the optical and structural properties during different stretching processes. This allowed us to investigate the effect of increasing the temperature on polymeric fibres and also on the necking phenomenon formed during the stretching of these fibres.

\section{Software configuration:-}

To carry out the above two targets, put both motors $\mathrm{W}_{1}$ and $\mathrm{W}_{2}$ to the same frequency and same total number of steps but let them to run in opposite directions as illustrated in operation of one point stretching mode. With no motion of motors while the thin heater is switched on and the CCD camera too, the camera will record changes of fringe shift of particular section through the continuous increase of temperature. In order to detect the stretching behaviour of certain fibre section at higher temperatures, connect the heater to a thermostatic controller and set the temperature to a selected value, as the temperature reaches this value and fixed then let motors to run as well as the camera. The recorded clip represents the stretching behaviour of the fibre's material at the selected temperature. This process can be repeated at another selected temperature and another fibre sample.

\section{Calculations:-}

The main task, in the case of detecting the refractive index profile at elevated temperature, is the matching between recorded temperature and the recorded video frames. To do this match, the temperature rising as function of time should recorded initially and then presented graphically. The recorded video clip is then decomposed into frames; each frame is characterized by the moment of capture. The time of certain frame can be dropped onto the temperature time curve to determine the temperature that corresponds to the capture time of the frame. On the other hand, the following equation is hold for this mode of operation as long as the temperature is fixed at a selected value.

$$
R_{e}=4 \pi r\left(\frac{f_{0}}{m}\right)
$$

Where: $R_{e}$ is the elongation speed, $\mathrm{r}$ is the radius of the cylinder that is rotating by the two motors $f_{0}$ is the rotational speed of two motors in step/sec and $\mathrm{m}$ is the number of steps per one complete revolution. 


\section{Cases of use:-}

This mode is useful for studying opto-thermo-mechanical of polymeric fibres. It helps to detect the structural variations of fibres at higher temperature.

\section{Experimental Results and Discussion:-}

In this work a hot-stage multi-mode opto-thermo-mechanical device was designed to study the online influence of increasing the temperature on the optical properties ofiPP samples. The designed multi-mode opto-thermo mechanical stretching system was attached to Pluta polarising interference microscope to allow the observation of the changes on the optical parameters during increasing the temperature of the fibre and during the stretching process of the samples and finally during the necking phenomenon.

\section{Online investigation of optical properties during temperature increasing:-}

The used sample in this work is isotactic as-spun undrawn monofilaments of polypropylene textile fibres, manufactured at spinneret take up speed $=250 \mathrm{~m} / \mathrm{min}$ and pump speed $=10 \mathrm{rpm}$. Samples of iPPfibres were fixed on the hot-stage and brought into the focus of the objective of the Plutapolarising interference microscope.During the optical investigation, iPP sample was immersed in a liquid with a suitable refractive index value $\left(\mathrm{n}_{\mathrm{L}}=1.499\right)$ at room temperature $\left(\mathrm{T}=25^{\circ} \mathrm{C}\right)$. The wavelength of the monochromatic light used was $546.1 \mathrm{~nm}$. The hot-stage heater is turned on to allow the heating of the fixed samples. Variations of the refractive index values were monitored by the online recording of the interference patterns.

The microinterferograms were analysed using the subfringe integration technique, which reduces the effect of noise [15]. The main idea of subfringe integration method is that the period of the sinusoidal signal, is divided into at least three or more buckets and integrates each bucket. Four integrating buckets, given by $\mathrm{I}_{1}, \mathrm{I}_{2}, \mathrm{I}_{3}$ and $\mathrm{I}_{4}$ (cf. [15]) in the spatial domain are used.

The phase $(\varphi)$ is giving by applying the equation:

$$
\varphi=\tan ^{-1}\left(\frac{\left(I_{1}+I_{2}\right)-\left(I_{3}+I_{4}\right)}{2\left(I_{2}-I_{1}\right)}\right)
$$

Figure (2) shows the flowchart of the designed software used in determining the refractive index profile and/or the birefringence profile in three dimensions. The measuring accuracy of the refractive index profile and/or birefringence profile using this model is $(0.003-0.001)$ [16, 17].

The patterns were analysed to extract the phase distribution during the heated process from which the refractive index values for light vibrating parallel and perpendicular along the fibre axis are determined. The refractive index profile is calculated according to the following relation [18], it was considered that, the graded index fibre is divided into number $(\mathrm{m})$ of very thin layers $(\mathrm{Q})$ with thickness $\mathrm{a}=\mathrm{R} / \mathrm{m}$, where $\mathrm{R}$ is the fibre radius. If the thickness of each layer is small enough, the variation of the value of the refractive index of the layer is negligible, and hence each layer has a constant refractive index value $\mathrm{n}(\mathrm{Q})$. The layer thickness plays an important role in accuracy of measurement. In other words, the thinner is the layer, the higher is the accuracy of calculation. Let $X_{Q}$ and $d_{Q}$ be the emerged and incidedntrays distance, where $\mathrm{Q}$ is the layer number. $\mathrm{h}$ is the interference spacing and $\lambda$ is the wavelength: 


$$
\begin{aligned}
\frac{\lambda Z_{Q}}{2 h} & =\sum_{i=1}^{Q-1}\left(2 n _ { i } ^ { \mathrm { k } } \left[\sqrt{(R-(i-1) \alpha)^{2}-\left(\frac{n_{0} d_{Q}}{n_{i}^{\mathrm{k}}}\right)^{2}}\right.\right. \\
& \left.\left.-\sqrt{(R-i \alpha)^{2}-\left(\frac{n_{0} d_{Q}}{n_{i}^{\mathrm{k}}}\right)^{2}}\right]\right) \\
& +2 n_{Q}^{\mathrm{k}} \sqrt{(R-(Q-1) \alpha)^{2}-\left(\frac{n_{0} d_{Q}}{n_{Q}^{\mathrm{k}}}\right)^{2}}-n_{0}\left[\sqrt{R^{2}-d_{Q}^{2}}+\sqrt{R^{2}-x_{Q}^{2}}\right]
\end{aligned}
$$

Where $\mathrm{k}$ denotes parallel and perpendicular.

This deduced expression [18] is used to determine the refractive index value for each layer $n(Q)$, by means of iteration. In this mathematical model, the refractive index values are determined with taking into account the transverse refraction of the incident rays, as well as, the longitudinal refraction. Transverse refraction may be neglected by setting $d_{Q}=X_{Q}$ to simplify the calculations and to avoid the iteration process when determining the refractive index profile.

Figure (3A) illustrates the calculated phase map of the captured interference patterns during the heating process at different temperatures for the case where the incident light is polarised parallel to the undrawn fibre axis.On the other hand, figure (3B) illustrates the phase map for the case of light vibrating perpendicular to the undrawn fibre axis. Figure (4) shows the 3D refractive index profile of the thermally treated filamentsin case of light vibrating parallel to the fibre axis. This figure clarifies that increasing the temperature causes an increment in the refractive index values across the fibre layers which indicates a rise in the refractive index distribution along the fibre axis, while figure (5) shows the 3D refractive index profile in case of light vibrating perpendicular to the fibre axis. According to this figure, a decrease in the refractive index distribution along the fibre axis, which reached a matching value at temperature $=70{ }^{\circ} \mathrm{C}$.

The optical orientation function $f_{\Delta}$ is obtained using the following equations (cf. [19]):

$$
f_{\Delta}=\frac{\Delta n_{a}}{\Delta n_{\max }}
$$

Where, $\Delta n_{\max }$ is the maximum birefringence, and it was found to equal 0.03 for iPP fibres [20].Figure (6) represents the effect of increasing the temperature on the orientation function of the different layers of iPP fibres, a noticeable increase in the molecular orientation is noticed for the layers on increasing the temperature.

\section{Effect of temperature on the drawing process:-}

The influence of the surrounding temperature on the distribution of the birefringence values at different position of the fibre during drawing process was investigated.The used sample in this work is isotactic as-spun undrawn monofilaments of polypropylene textile fibres, manufactured at spinneret take up speed $=150 \mathrm{~m} / \mathrm{sec}$ with temperature zone equal to $350-450{ }^{\circ} \mathrm{C}$. The sample is fixed from its ends on the two motors $\left(\mathrm{W}_{1}, \mathrm{~W}_{2}\right)$ passing through the hot-stage, (figure 1), to carry out the thermal treatment during the stretching process. The sample was immersed in a liquid with a suitable refractive index value $\left(\mathrm{n}_{\mathrm{L}}=1.500\right.$ at room temperature $\left.\mathrm{T}=25^{\circ} \mathrm{C}\right)$. The wavelength of the monochromatic light used was $546.1 \mathrm{~nm}$. The hot-stage multi-mode stretching device was attached to Pluta polarising interference microscope, and the fibre sample was brought to be inthe focus of the objective lens.The speed of stretching was adjusted to be $4 \mathrm{step} / \mathrm{sec}$, which was fixed during the different stretching processes.First, the sample was heated until it reaches a certain temperature ranges at $\left(25,50,60\right.$, and $\left.70{ }^{\circ} \mathrm{C}\right)$ respectively, then a temperature controller was used to fix every mentioned temperature during the stretching process in the range $(\mathrm{Dr}=1.2-1.7)$. During the stretching process, the interferograms were recorded continuously, 
which allows the online study of the variations of the optical parameters that are determined from the interferograms.

The patterns were analysed to extract the phase distribution during the heating process from which the birefringence values are determined. The birefringence profile is calculated according to the following relation, which considers the transverse refraction of the incident beam [21]:

$$
\Delta n_{Q}=\left[\frac{1}{\mathrm{R}-(\mathrm{Q}-1) \mathrm{a}}\right]\left[\frac{\lambda \Delta Z_{Q}}{2 b}-a \sum_{j=1}^{j=Q-1} \Delta n_{j}\right] \text { (5) }
$$

Where; $\Delta \mathrm{n}$ : birefringence, $\mathrm{Q}$ : layer number, $\mathrm{j}$ : integer number $(\mathrm{j}=1$ : $\mathrm{Q}-1), \lambda$ : wavelength of monochromatic light used, Z: fringe shift, b: interfringe spacing, R: the radius of the fibre, a: layer thickness.

Figure (7) shows the 3D birefringence profile at differentdraw ratios ranged from(DR $=1.2-1.7)$ at temperature $\mathrm{T}$ $=25{ }^{\circ} \mathrm{C}$. This figure shows an increase in the birefringence during the stretching process as the draw ratios increase. Also for different temperatures i.e. 50,60 and $70{ }^{\circ} \mathrm{C}$, the increase in the birefringence was observed during the stretching process as shown in figures (8, 9 and 10). Moreover, for the same draw ratio Dr=1.6, for example, it was noticed that, the birefringence values were higher at higher temperature. According to this behaviour, either increasing the temperature or increasing the draw ratio induces more orientation of the molecular chains observed as an increase in the birefringence value. The distribution of the birefringence values helps in detecting different geometrical deformations during the stretching process. This is shown in figure (8) for DR $=1.3$ when the surrounding temperature is $50{ }^{\circ} \mathrm{C}$. In this figure a necking phenomenon takes place at this draw ratio causing deformed distribution of the birefringence values having the shape of the neck. Also, for the surrounding temperature equal $60{ }^{\circ} \mathrm{C}$, the neck deformation is detected at draw ratio Dr=1.4 as shown in figure (9). And another neck is shown in figure (10), when the temperature is $70{ }^{\circ} \mathrm{C}$ and draw ratio is $\mathrm{Dr}=1.6$. So, it can be concluded that the creation of necking deformation depending on the surrounding temperature and draw ratio for the constant stretching velocity.

Thedetermined3D birefringence profile presents accurate measurements of the birefringence values at different positions of the stretched samples. It may noted that, in all of the following birefringence profiles, the birefringence scale was not fixed for all graphs, this was done to allow more details to be observed rather than fixing the scale of the birefringence axis which may suppress the details of the distribution of the birefringence for the inner layers of the investigated samples.

\section{Effect of temperature on the necking phenomenon:-}

One of the main features of the multi-mode stretching device is its ability to investigate the effect of increasing the temperature on the necking phenomenon observed during the stretching process of iPP fibres. The used sample in this work is isotactic as-spun undrawn monofilaments of polypropylene textile fibres, manufactured at spinneret take up speed $=150 \mathrm{~m} / \mathrm{sec}$ with temperature zone equal to $350-450{ }^{\circ} \mathrm{C}$. The iPP fibre sample was fixed from its ends on the two motors $\left(\mathrm{W}_{1} \& \mathrm{~W}_{2}\right)$, (figure 1), passing through the hot-stage. The used device was attached to Pluta polarising interference microscope. The fibre was immersed in a liquid with refractive index value $\left(\mathrm{n}_{\mathrm{L}}=1.5\right)$. The wavelength of the light used was $546.1 \mathrm{~nm}$. The fixed iPP fibre sample was stretched until the necking region is observed in the field of view. Once the necking is observed, the stretching process is stopped and the heater is turned on. The online recording of the interference pattern for iPP fibre with necking deformation during heating processes allowed us to investigate the effect of heating on the necked sample.

The necking phenomenon usually occurs when a homogeneous polymeric fibre is stretched uniaxially. In this case the fibre is deformed into three microscopic regions according to the morphological model of Shimizu et al. [22] and the molecular model of Peterlin [23]. These regions are: i) The as spun, part of fibre (before neck). ii) The neck shoulder (neck zone as super drawing), and iii) The drawn fibre part (after neck).

Figure (11) represents the acquired phase maps of two-beam interference patterns captured during the heating process. In addition, figure (12) represents the unwrapped phase distribution in 3D along necked iPP fibres at different temperatures. The necking regions were noticed as localised phase changes along the fibre's axis. From the observed phase maps and the 3D unwrapped phase distribution (figures $11 \& 12$ ), necking propagation can be noticed as the temperature increases. To clarify this phenomenon the phase maps (figure 11) are remarked to be easy for identification the propagation of the necking 
along the fibre axis during the increasing of temperature. At temperature $\left(27^{\circ} \mathrm{C}\right)$, the neck shoulder was observed at fringe number 5 , at $\left(28^{\circ} \mathrm{C}\right)$, the neck shoulder became between fringe number 5 and 6 , at $\left(29^{\circ} \mathrm{C}\right)$, the neck shoulder was detected near to fringe number 6 , at $\left(30^{\circ} \mathrm{C}\right)$, the neck shoulder was located at fringe number 6 , at $\left(32^{\circ} \mathrm{C}\right)$, the neck shoulder was between fringe number 6 and 7 , at $\left(33^{\circ} \mathrm{C}\right)$, the neck shoulder was noticed near to fringe number 7 , finally, at $\left(34^{\circ} \mathrm{C}\right)$, the neck shoulderwas observed at fringe number 7. It was noticed that, increasing the temperatures may cause the localised necking to transfer to another position. In this case, we can conclude that increasing temperature causes the necking to propagate along the fibre axis.

To calculate the speed of necking propagation interferometrically from the fringe shift profile, the neck profile is noticed when changes passes between two points along the fibre axis, the spacing distance between the two points $(\Delta \mathrm{x})$, during the interval time $(\Delta \mathrm{t})$. The speed of propagation is given from the equation $\mathrm{V}_{\mathrm{p}}=(\Delta \mathrm{x} / \Delta \mathrm{t})$. This process is carried out at different positions along fibre axis to determine the mean speed of propagation. It was noticed that the speed of propagation is nearly constant along fibre axis during the propagation process. The mean speed of propagation is $\mathrm{V}_{\mathrm{p}}=1.0635 \mu \mathrm{m} / \mathrm{sec}$.

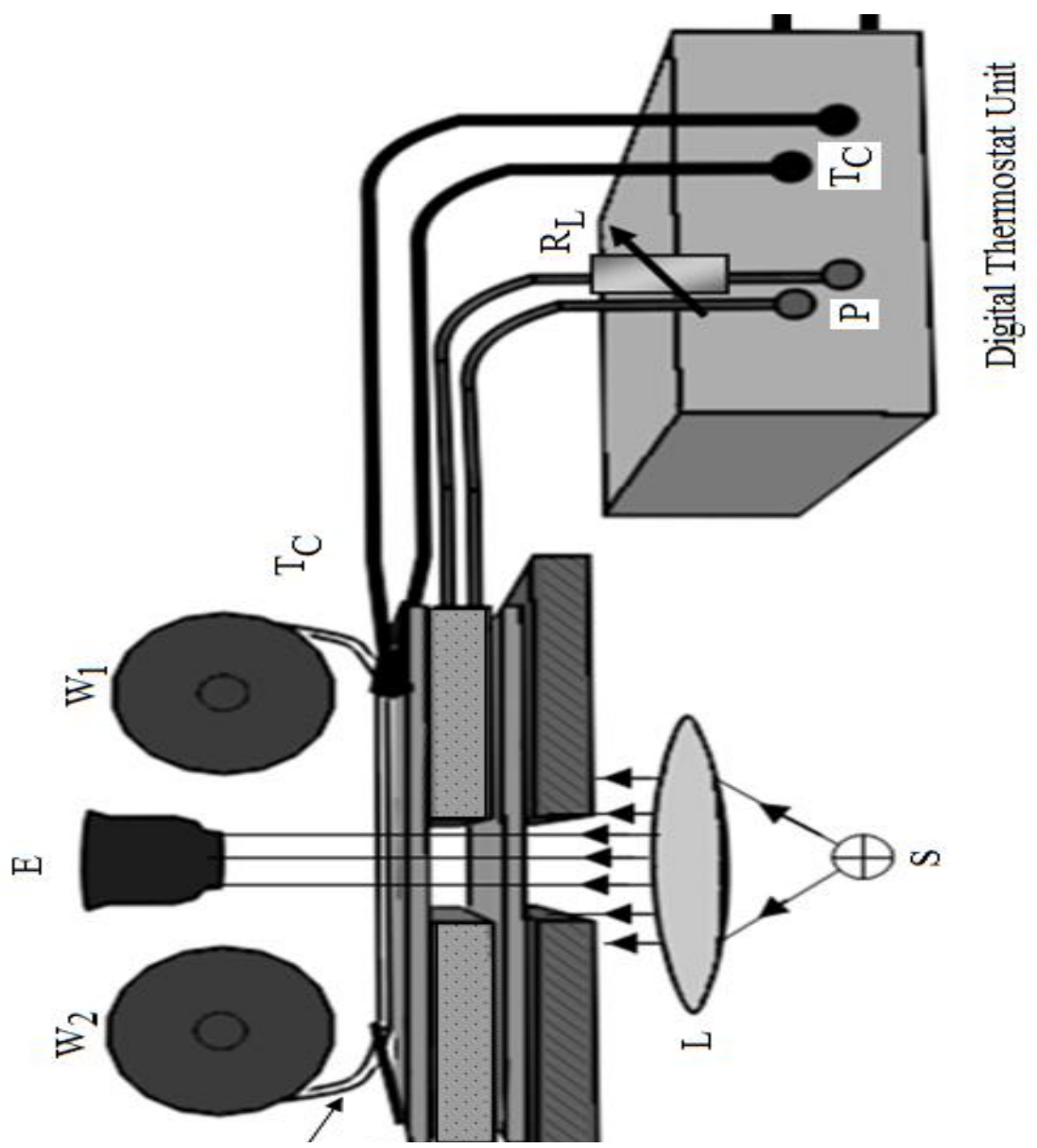

Figure 1:- A schematic diagram of multi-mode opto-thermo mechanical stretching system. Where, M: Microscope stage, G1, G2: glass slides, H: flate heater (at 20w, 110v), F: fibre under test, W1, W2 : rotating wheels attached to stepper motors, E: microscope eyepiece, L: collimating lense, S: white light source, TC: tip of K-type thermocouple and it's terminals, $R_{L}$ : variable load resistance, P: power terminals for heater. 


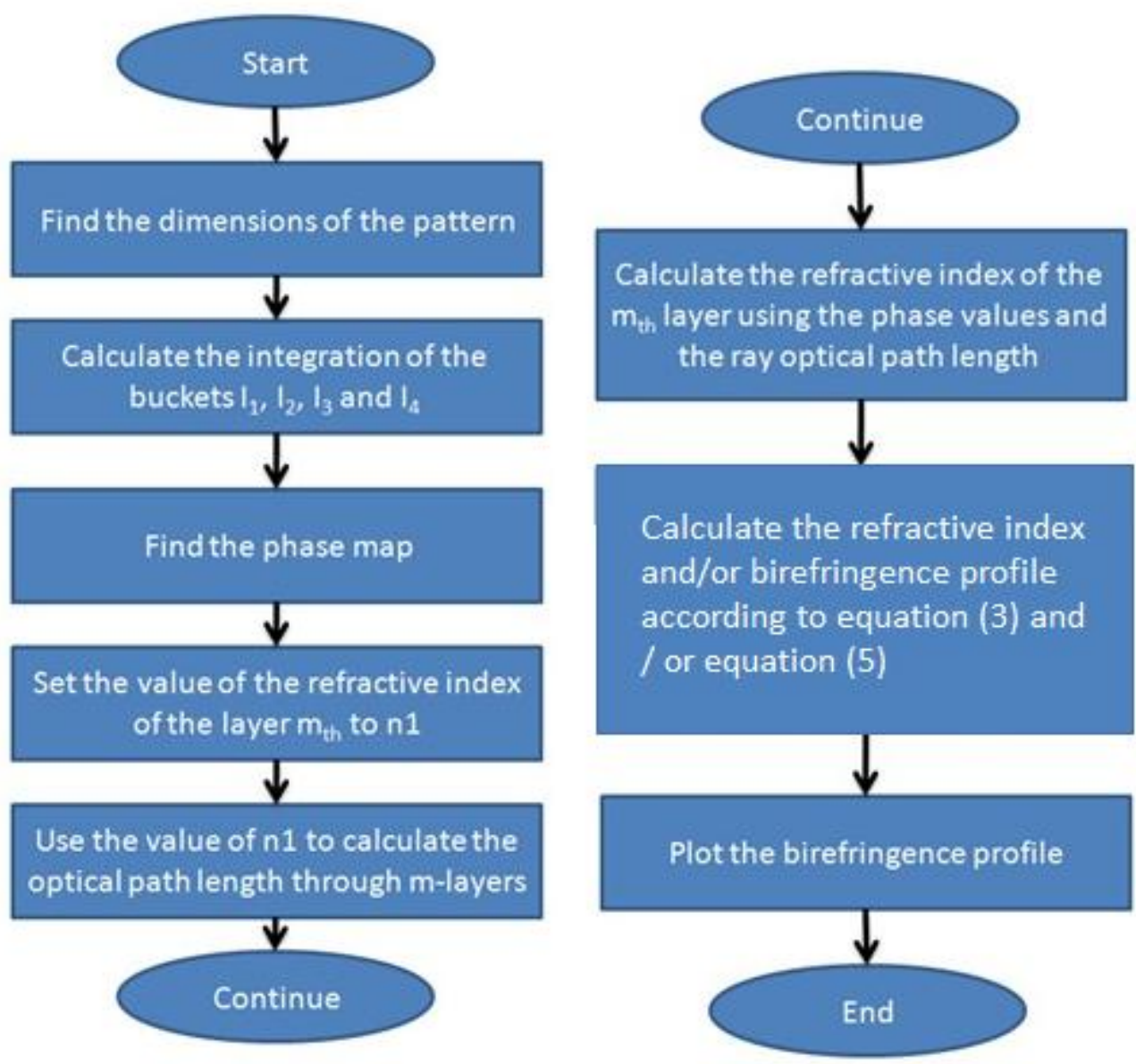

Figure 2:- Flowchart of the used software for fringe analysis.

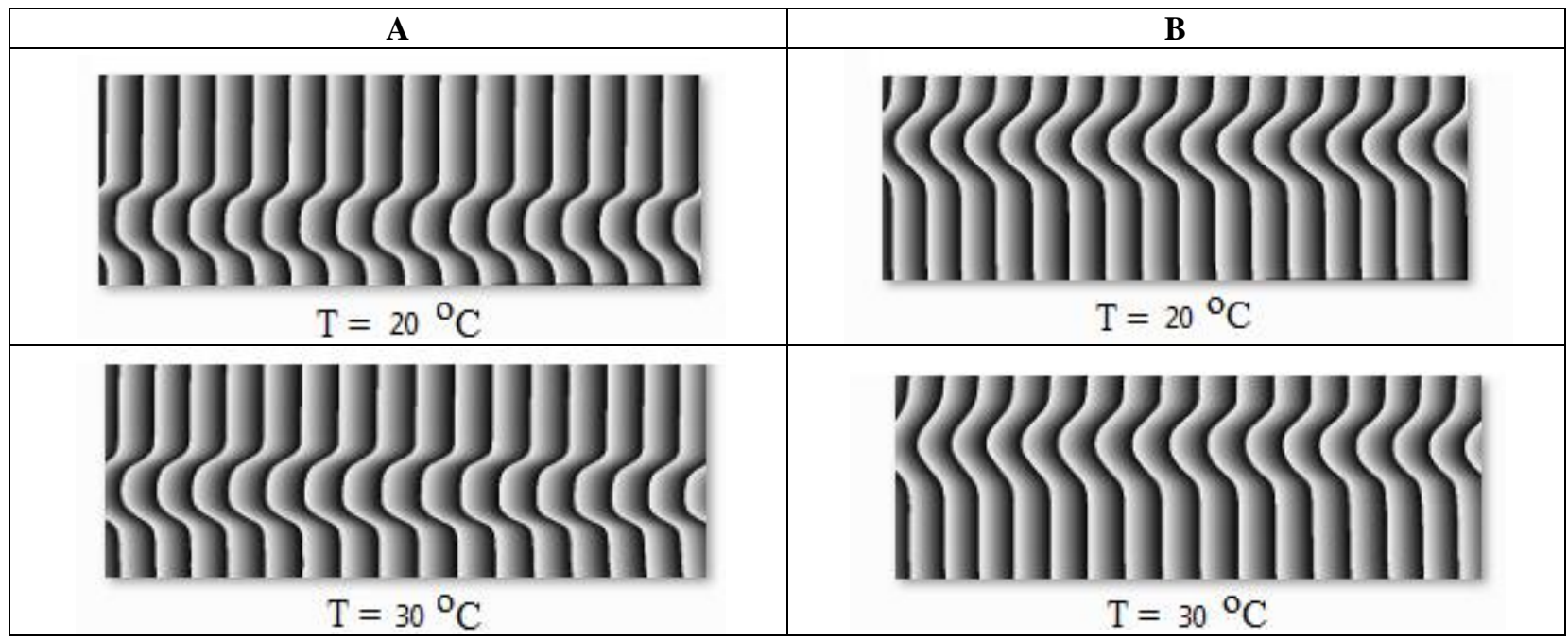




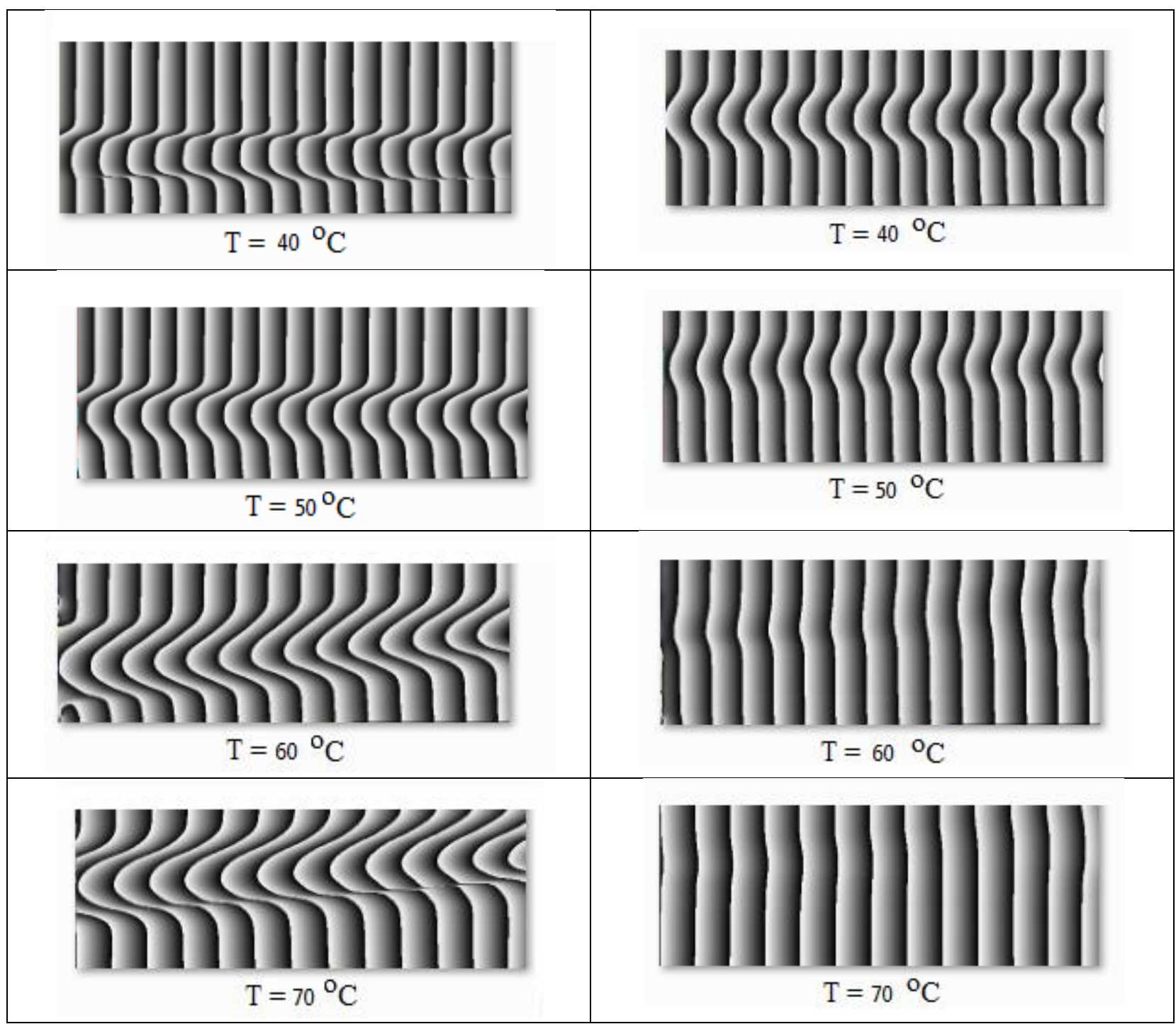

Figure 3:- (A) Phase map obtained from the recorded interferograms during the heating process at different temperatures $\left(20,30,40,50,60\right.$ and $\left.70{ }^{\circ} \mathrm{C}\right)$ for the case where the incident light is polarised parallel to the fibre axis. (B) Phase map for the case where the incident light is polarised perpendicular to the fibre axis. 


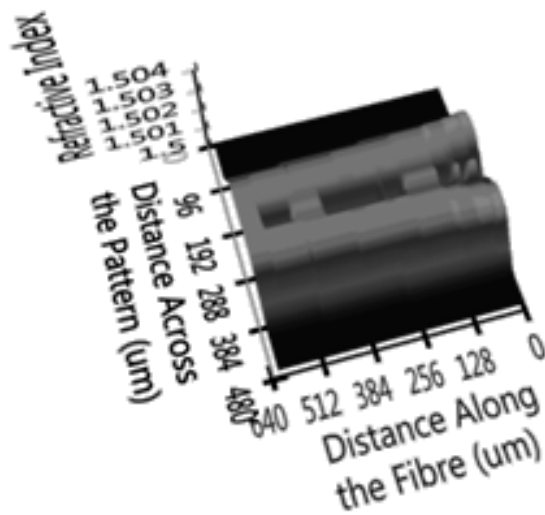

$\mathrm{T}=20^{\circ} \mathrm{C}$
흘

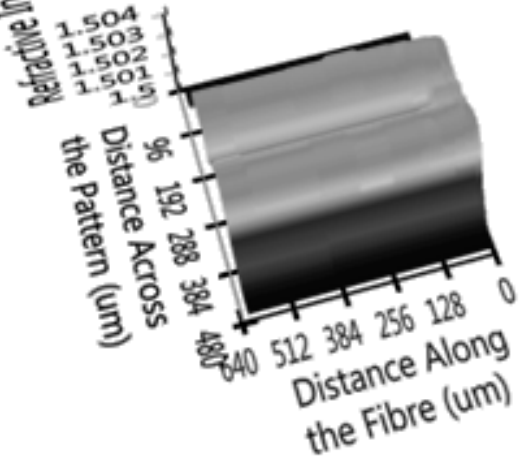

$\mathrm{T}=50{ }^{\circ} \mathrm{C}$

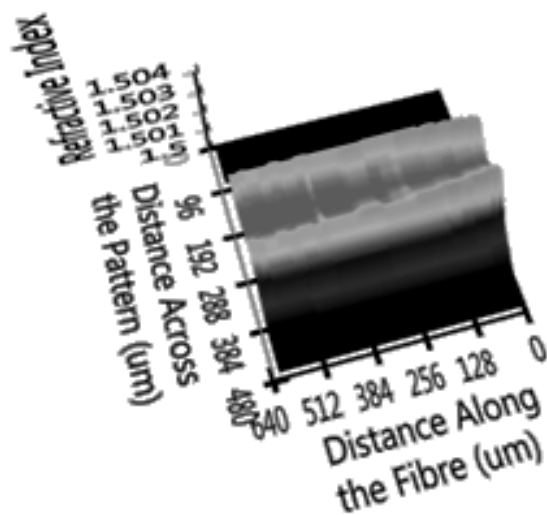

$\mathrm{T}=30{ }^{\circ} \mathrm{C}$

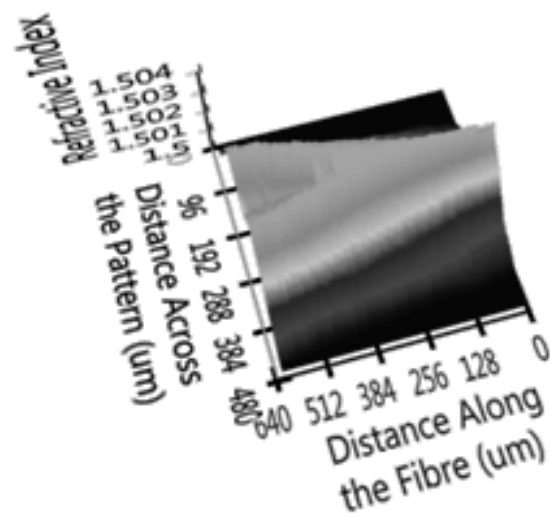

$\mathrm{T}=60{ }^{\circ} \mathrm{C}$

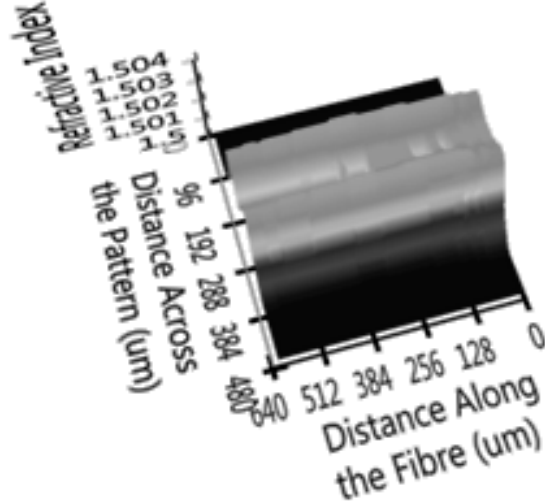

$\mathrm{T}=40^{\circ} \mathrm{C}$

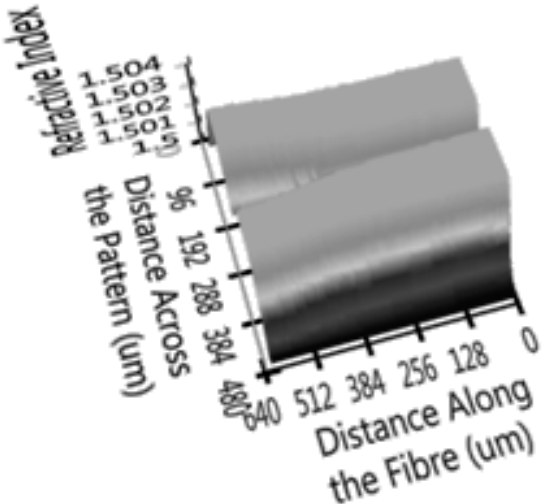

$\mathrm{T}=70{ }^{\circ} \mathrm{C}$

Figure 4:- The3Drefractive index profileduring the heating process at different temperatures $(20,30,40,50,60$ and $70{ }^{\circ} \mathrm{C}$ ) for the case where the incident light is polarised parallel to the fibre axis. 
흘
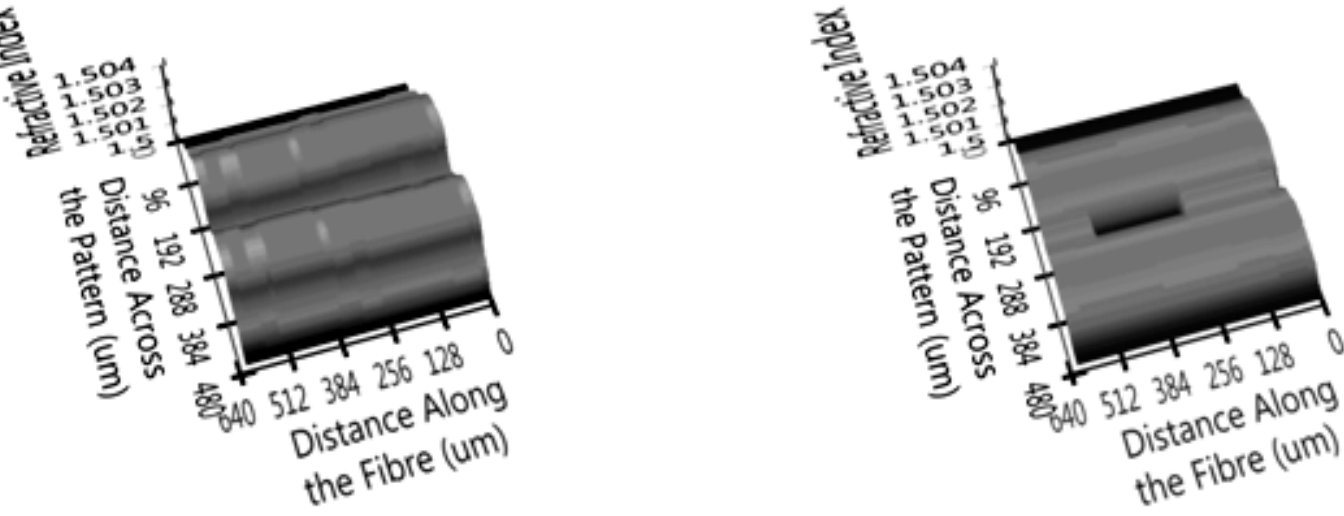

$\mathrm{T}=20^{\circ} \mathrm{C}$

$\mathrm{T}=50{ }^{\circ} \mathrm{C}$

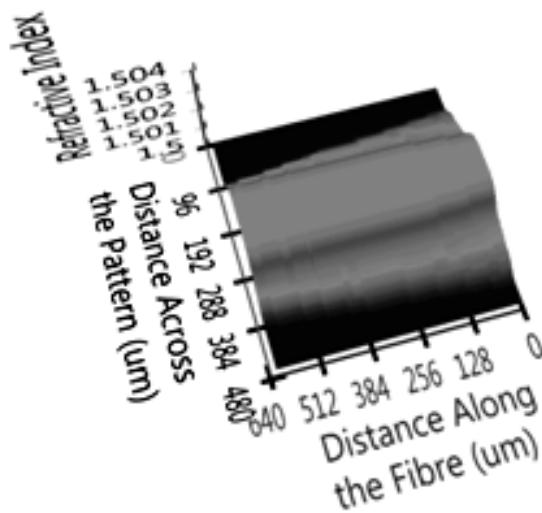

$\mathrm{T}=30^{\circ} \mathrm{C}$

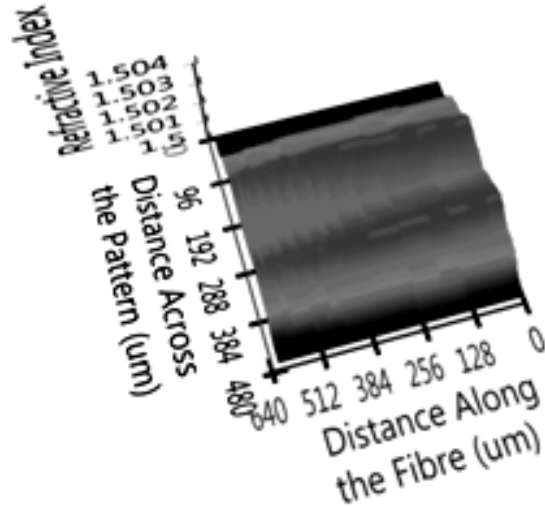

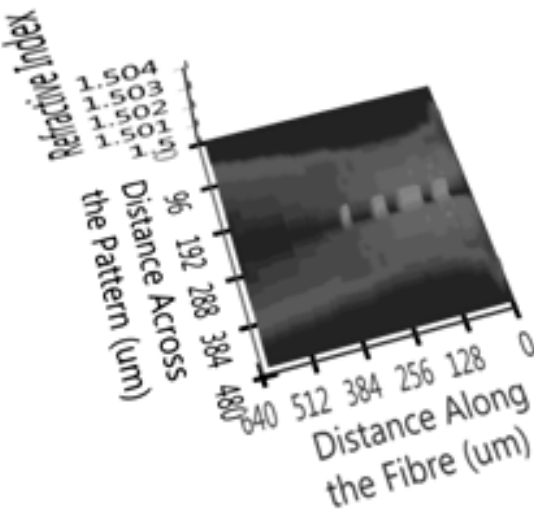

$\mathrm{T}=60{ }^{\circ} \mathrm{C}$

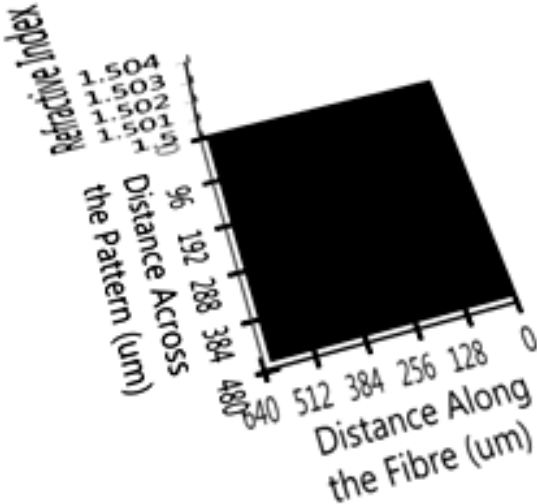

$\mathrm{T}=70{ }^{\circ} \mathrm{C}$

Figure 5:- The3Drefractive index profileduring the heating process at different temperatures $(20,30,40,50,60$ and $70{ }^{\circ} \mathrm{C}$ ) for the case where the incident light is polarised perpendicular to the fibre axis. 


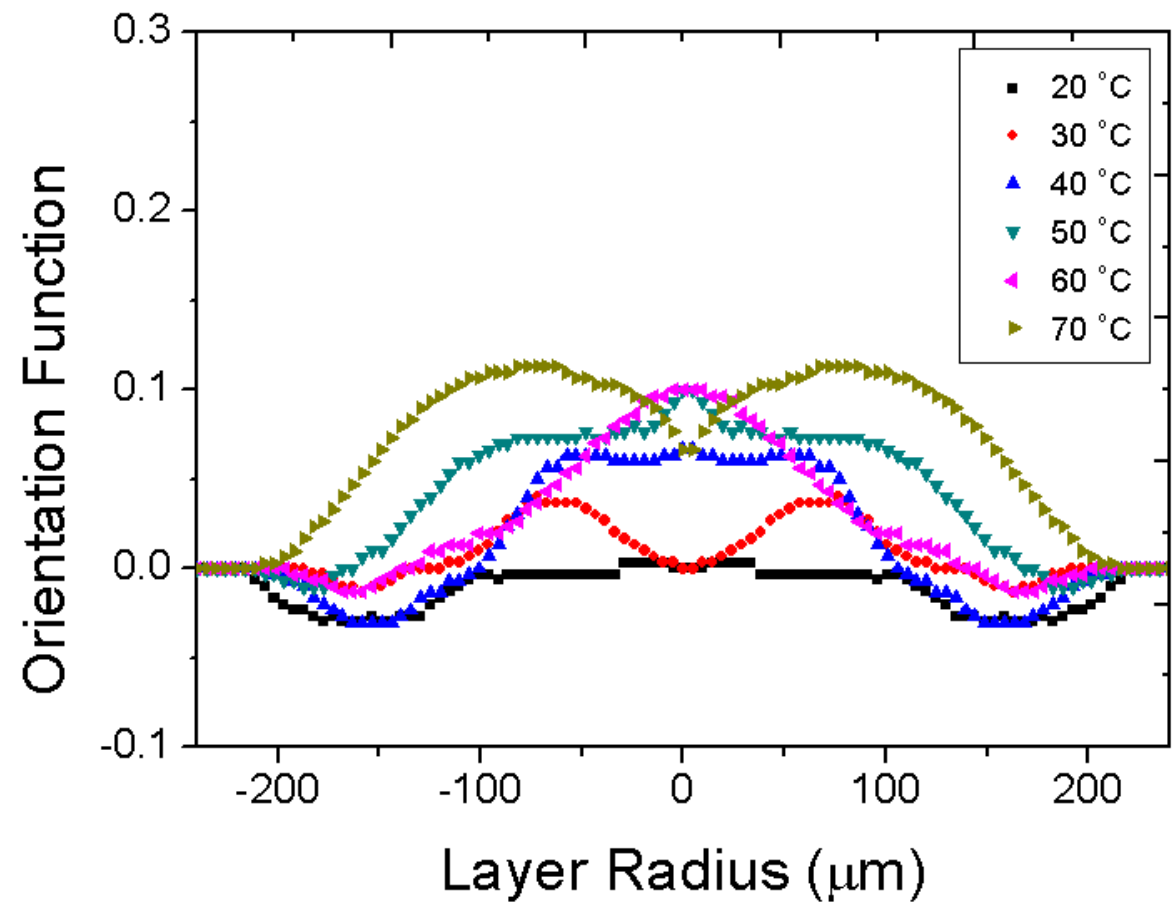

Figure 6:- Therelation betweenthe orientation function and different layers of iPP fibres.

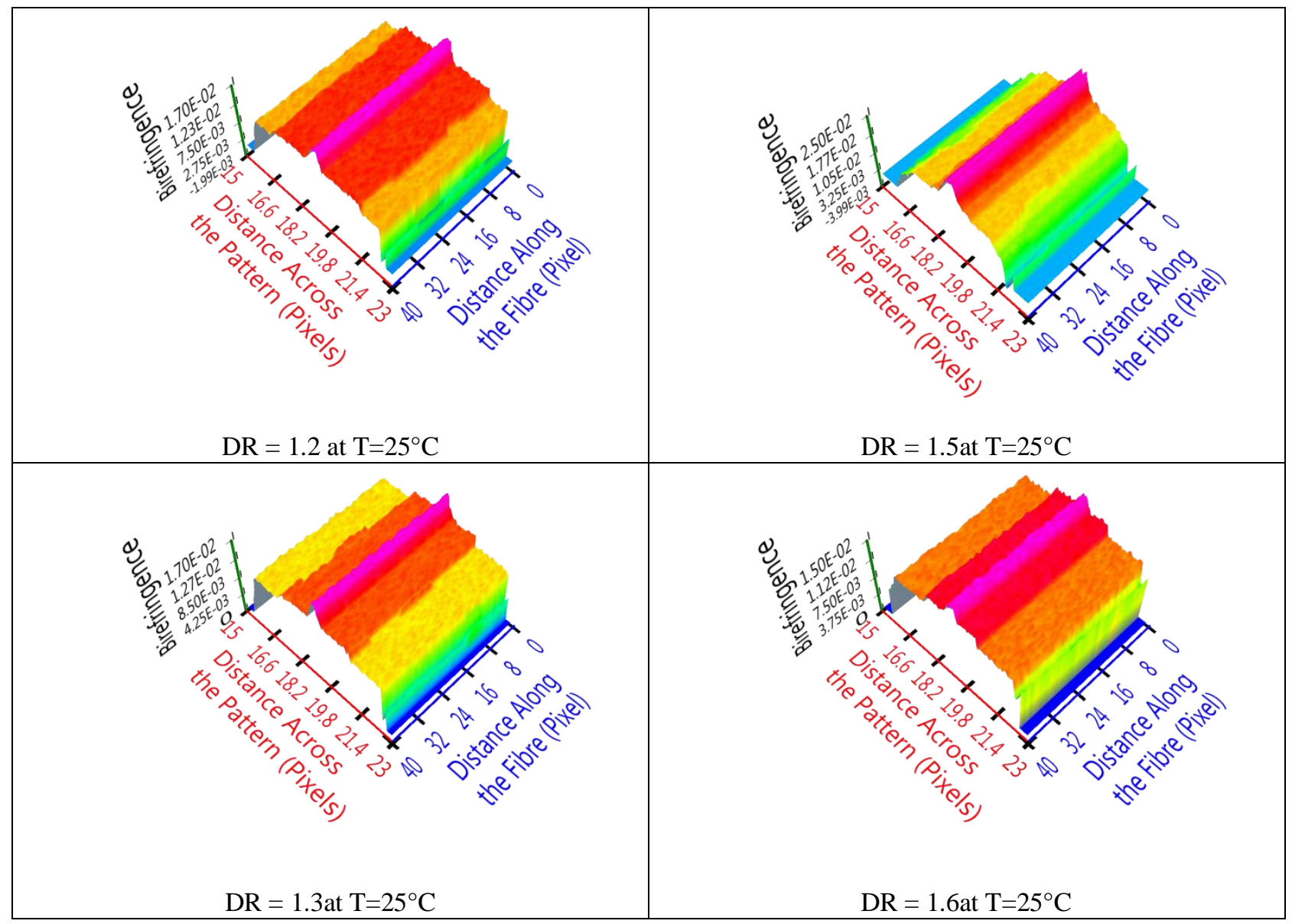



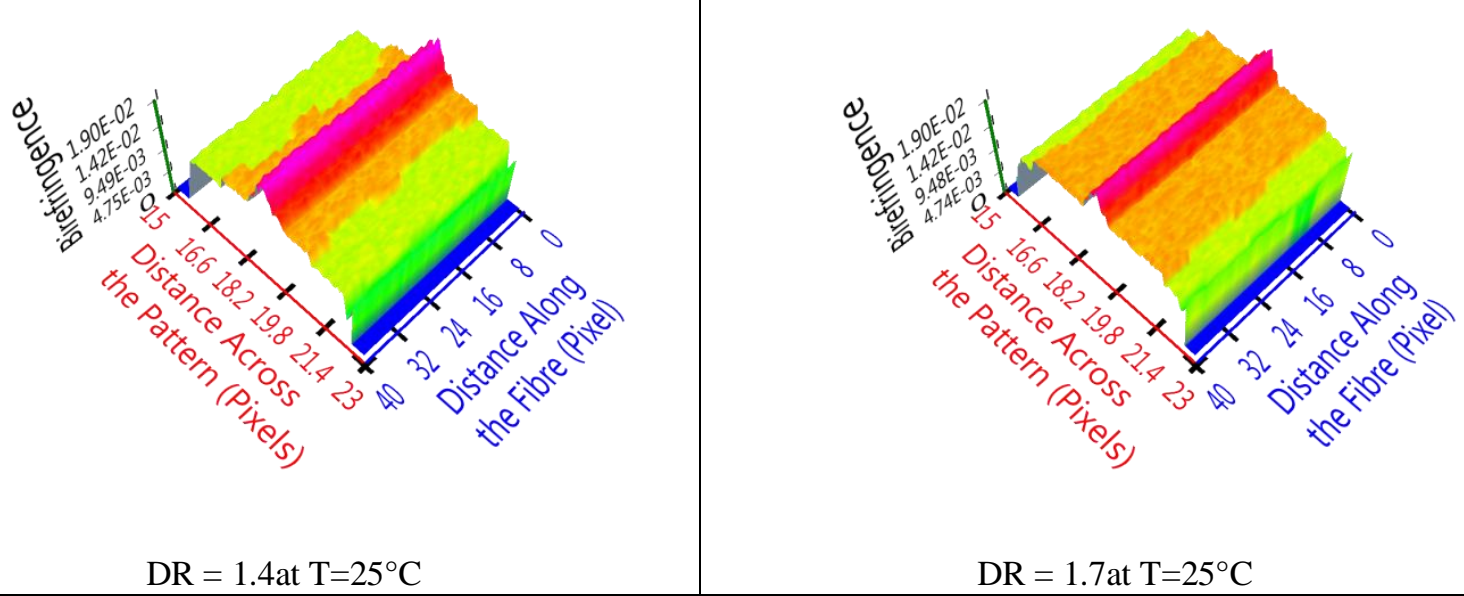

Figure 7:- The 3D birefringence profile during stretching fibre at temperature $25^{\circ} \mathrm{C}$ and stretching speed $=4 \mathrm{step} / \mathrm{sec}$, at draw ratios $(1.2,1.3,1.4,1.5,1.6$ and 1.7).

(1)



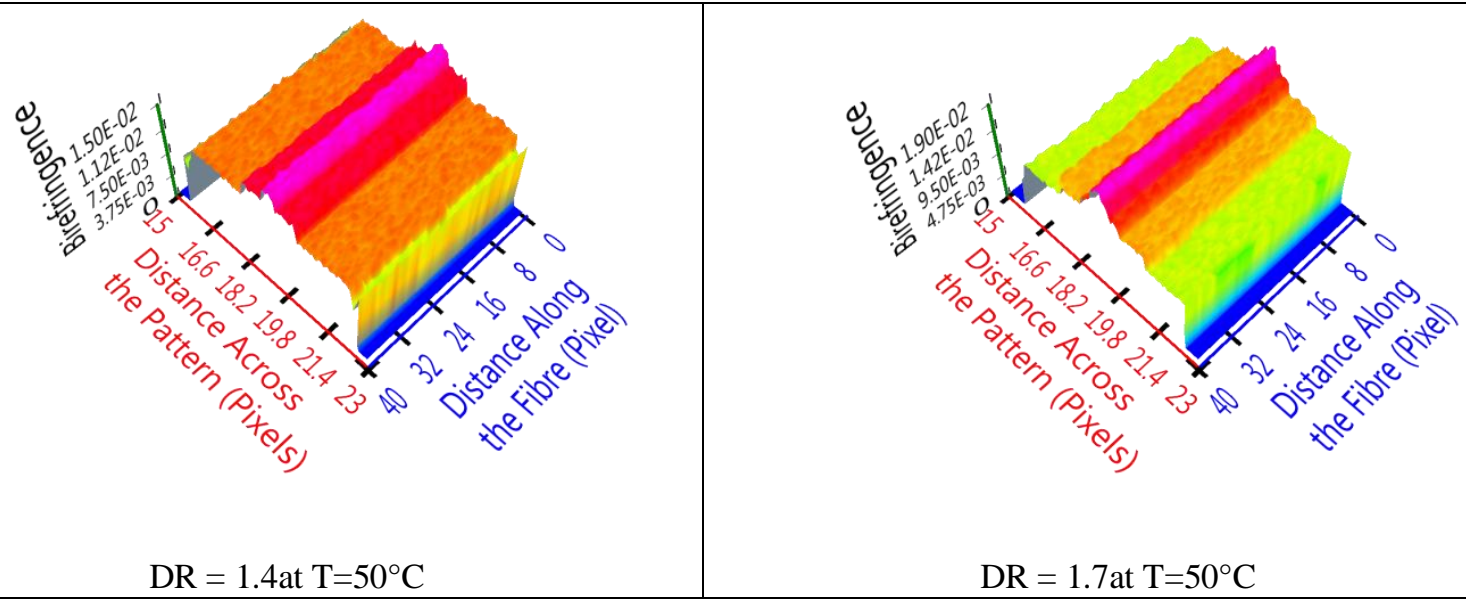

Figure 8:- The 3D birefringence profile during stretching fibre at temperature $50^{\circ} \mathrm{C}$ and stretching speed $=4 \mathrm{step} / \mathrm{sec}$, at draw ratios $(1.2,1.3,1.4,1.5,1.6$ and 1.7$)$.

(1)



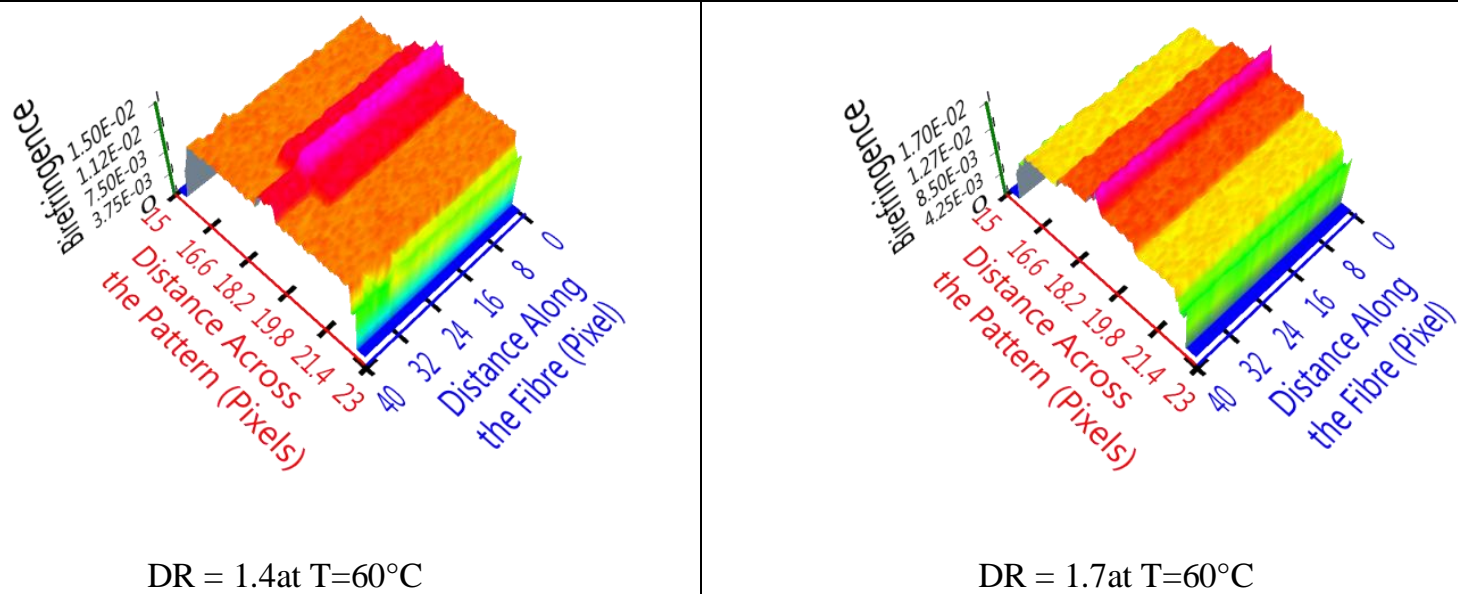

Figure 9:- The 3D birefringence profile during stretching fibre at temperature $60{ }^{\circ} \mathrm{C}$ and stretching speed $=4 \mathrm{step} / \mathrm{sec}$, at draw ratios $(1.2,1.3,1.4,1.5,1.6$ and 1.7).

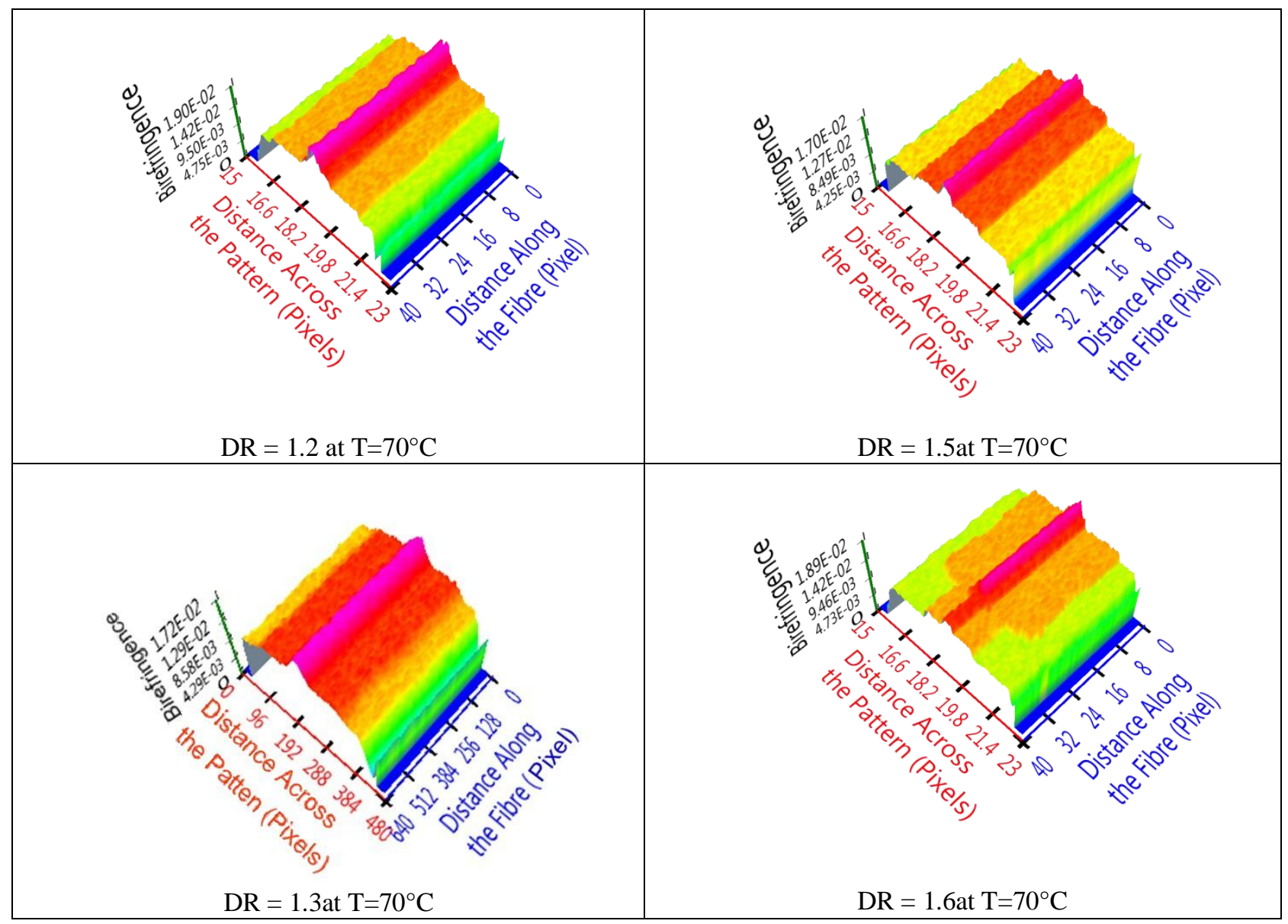



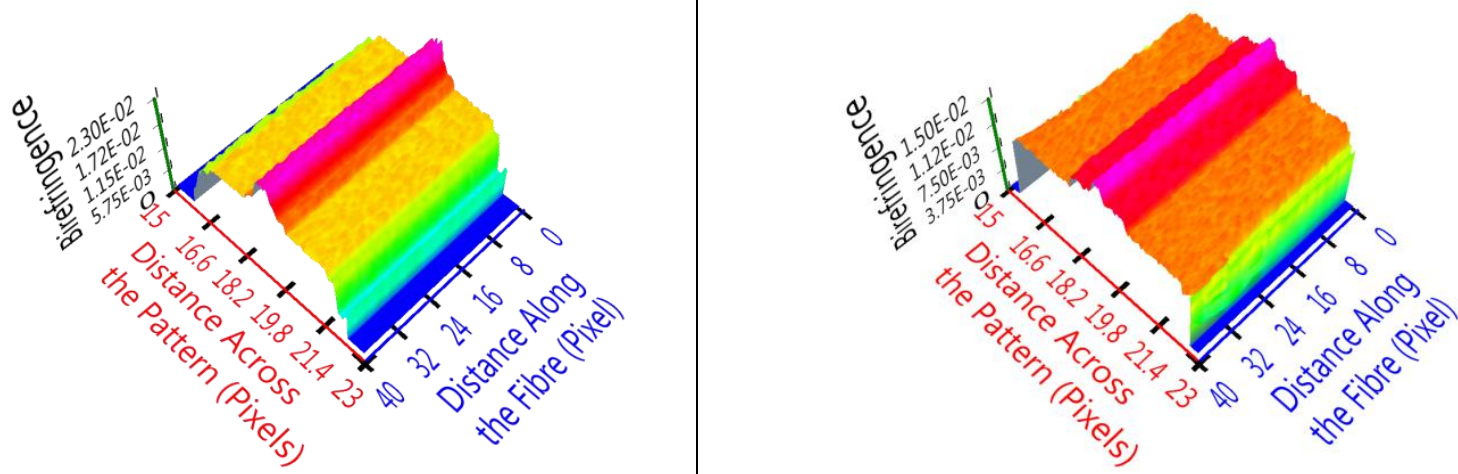

$\mathrm{DR}=1.4 \mathrm{at} \mathrm{T}=70^{\circ} \mathrm{C}$

$\mathrm{DR}=1.7$ at $\mathrm{T}=70^{\circ} \mathrm{C}$

Figure 10:-The 3D birefringence profile during stretching fibre at temperature $70{ }^{\circ} \mathrm{C}$ and stretching speed $=4$ step/sec, at draw ratios $(1.2,1.3,1.4,1.5,1.6$ and 1.7).

\begin{tabular}{|c|c|}
\hline $\begin{array}{l}\begin{array}{l}\text { Before } \\
\text { Necking }\end{array} \\
\text { Shoulder } \\
\mathrm{T}=27{ }^{\circ} \mathrm{C} \\
\text { Necking }\end{array}$ & 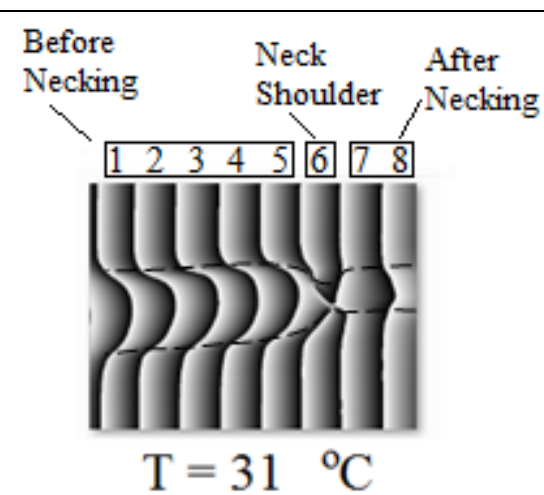 \\
\hline 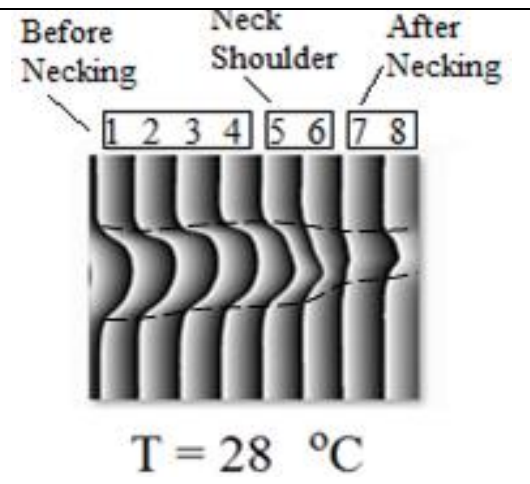 & $\begin{array}{c}\text { Before } \\
\text { Necking }\end{array}$ \\
\hline $\begin{array}{l}\begin{array}{l}\text { Before } \\
\text { Necking }\end{array} \\
\text { Shoulder }\end{array}$ & $\begin{array}{l}\text { Before } \\
\text { Necking }\end{array}$ \\
\hline
\end{tabular}




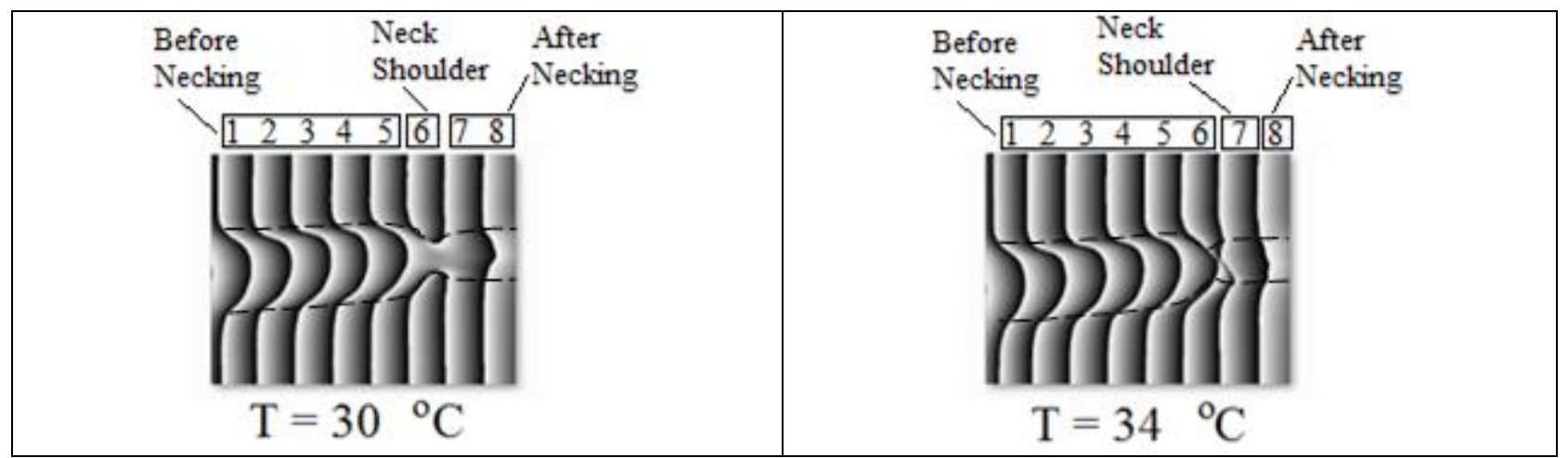

Figure 11:- Phase map obtained from the recorded interferograms during the heating process of necking phenomenon at different temperatures $\left(27,28,29,30,31,32,33\right.$ and $\left.34^{\circ} \mathrm{C}\right)$.

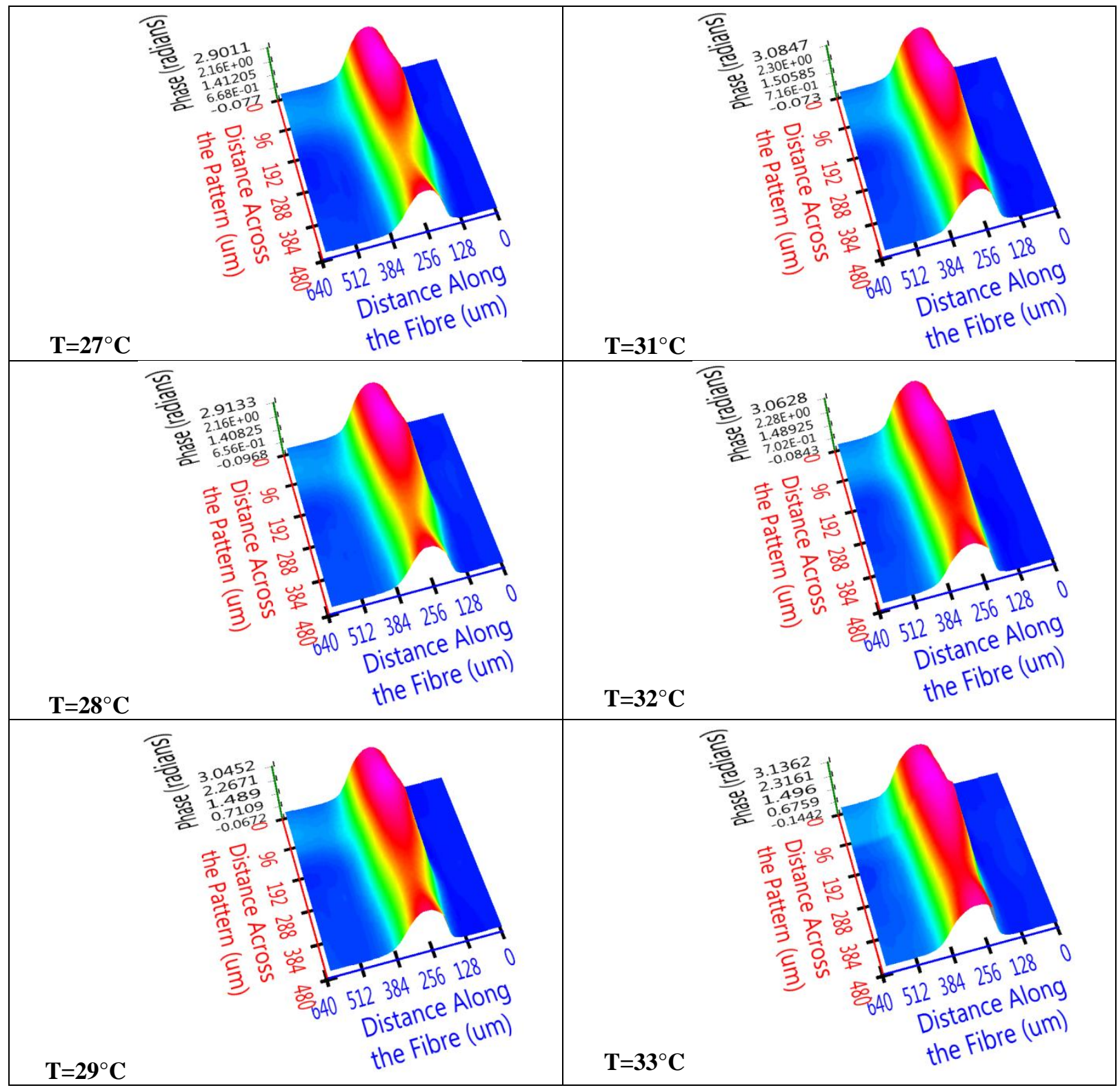




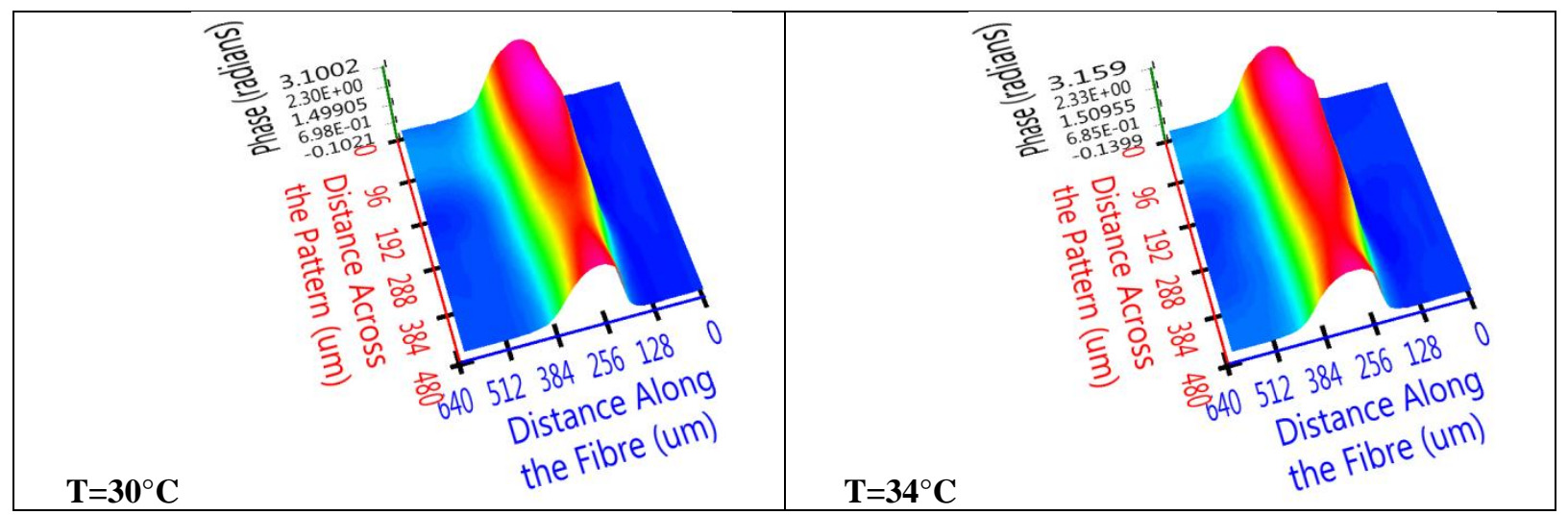

Figure 12:- The 3D unwrapped phase distribution during the heating process of necking phenomenon at different temperatures $\left(27,28,29,30,31,32,33\right.$ and $\left.34^{\circ} \mathrm{C}\right)$.

\section{Conclusion:-}

A multi-mode opto-thermo mechanical stretching device attached toPluta polarising interference microscope is constructed. The advantage of this device is the online determination of the optical parameter of heated fibres at different temperatures. Using this device for iPP fibre clarified that; temperature increment resulted higher orientation of heated fibres. Also it is concluded that the surrounding temperature of the fibre is an effective parameter, as well as the draw ratio and stretching velocity, for the creation of necking deformation. Also using this device allowed us to investigate the effect of varying the surrounding temperature on the necking phenomenon. In this study, upon increasing the temperature, necking region began to propagate.

\section{References:-}

1. M. Denac, V. Musil, I. Smit, "Structure and mechanical properties of talc-filled blends of polypropylene and styrenic block copolymers". J.Polym. Sci. Part B, 2004; 42: 1255-1264.

2. R. C. L. Dutra, B. G. Soares, E. A. Campos, J. D. G. De Melo, J. L. G. Silvia, " Composite materials constituted by a modified polypropylene fiber and epoxy resin", J. Appl.Polym. Sci. 1999; 73: 69-73.

3. M. Aboulfaraj, C. G'Sell, B. Ulrich, A. Dahoun, "In situ observation of the plastic deformation of polypropylene spherulites under uniaxial tension and simple shear in the scanning electron microscope", Polymer, 1995;36:731.

4. J. Sweeney, I. M. Ward, "The modeling of multiaxial necking in polypropylene using a sliplink-crosslink theory", J.Rheol, 1995;39:861.

5. W. G. Hu, K. S. Rohr, "Polymer ultradrawability: the crucial role of $\alpha$-relaxation chain mobility in the crystallites",ActaPolym. 1999;50:271.

6. K. W. Zbigniew, "Formation of Synthetic Fibres", ch7, Gordon and Breuch Science Publishers, New York, (1977).

7. Akihiko Toda, Chiyoko Tomita, MasamichiHikosaka, Yu Hibino, Hideki miyaji, ChisatoNoormura, ToshitakeSuzui, and Hideaki Ishihara, "Thermo-mechanical coupling and self-excited oscillation in the neck propagation of PET films", Polymer, 2002; 43: 947.

8. R. C. Faust, "The Determination of the Refractive Indices of Inhomogeneous Solids by Interference Microscopy", Proc. Phys. Soc. B, 1954; 67: 138-148.

9. A. A. Hamza, I. M. Fouda, K. A. El-Farahaty, K. A. El-Sayed, " Effects of Temperature on the birefringence Variations of Wool Fibres",Acta Phys. Pol. A: 1988; 73: 767.

10. A. A. Hamza, T. Z. N. Sokkar, K. A.El-Farahaty, H. M. El-Dessoky, "Influence of temperature on the optical and structural properties along the diameter of: I. Polymer fibres", J. Phys.: Condens. Matter 1999; 11: 5331.

11. A.E. Belal, A.A. Hamza, T.Z.N. Sokkar, K.A. El-Farahaty, K.M. Yassien, "Opto-thermal behavior of polypropylene fibres using a modified hot-stage attached to the interference microscope", Polymer Testing 2002; 21: 877-882.

12. A. A. Hamza, T. Z. N. Sokkar, M. A. El-Bakary, A. M. Ali, "An intereferometric method for studying the influence of temperature on the mean refractive indices and cross-sectional area of irregular fibres", Polymer Testing 2003; 22: 83-91. 
13. H. M. El-Dessouky, "Interferometric Investigation of the Optical and Structural Properties of Thermally Treated Polyethylene Fibers", Fibers and Polymers, 2009;10:280-284.

14. T.Z.N. Sokkar, M.M. El-Tonsy, M.A. El-Morsy, S.M. El-Khateep, M.I. Raslan, " Multi-mode opto-thermo mechanical stretching system for determination of $3 D$ refractive index along the axis of stretched and / or heated fibres", Optics \& Laser Technology,2011; 43: 1054-1060.

15. M.A. El-Morsy, K. Harada, M. Itoh, T. Yatagai, "A subfringe integration method for multiple-beam Fizeau fringe analysis", Optics \& Laser Technology. 2003; 35: 225.

16. M. Pluta, "A Double Refracting Interference Microscope with Continuously Variable Amount and Direction of Wavefront Shear", Journal of Modern Optics, 1971; 18: 661-675.

17. M. Pluta, "Interference Microscopy of Polymer Fibres", J. Microsc. 1972; 96: 309.

18. A. A. Hamza, A. M. Ghander, T. Z. N.Sokkar, M. A. Mabrouk and W. A. Ramadan, "On the determination of the refractive index of a fibre. II. Graded index fibre", Pure Appl Opt 1995; 4: 161-177.

19. I. M. Ward, "Optical and mechanical Anisotropy in Crystalline Polymers", Proc. Phys. Soc. 1962; 80: 11761188.

20. H. M. El-Dessouky, C. A. Lawrence, A. M. Voice, E. L. V. Lewis and I. M. Ward, "An interferometric prediction of the intrinsic optical properties for cold-drawn iPP, PTFE and PVDF fibres”, J. Opt. A: Pure Appl. Opt. 2007; 9: 1041-1047.

21. T. Z. N. Sokkar, H. M. El-Dessouky, M. A. Shams-Eldin, M. A. El-Morsy, "Automatic fringe analysis of twobeam interference patterns for measurement of refractive index and birefringence profiles of fibres", Optics and Lasers in Enginering 2007; 45: 431-441.

22. J. Shimizu, N. Okui, T. Kikutani, "In high speed fibre spinning", A. Ziabicki and H. Kawaieds. Wiley, New York, 1985; 173.

23. A. Peterlin, "Molecular model of drawing polyethylene and polypropylene", J. Matter. Sci., 1971; 6: 490. 